\title{
A Study on the Dynamic Adjustment of Pressure Relief Gas Drainage Drilling in Mined-Out Areas
}

\author{
Bo Bi, Jianbing Meng, Bengliang Cheng \\ National Engineering Research Center for Coal Gas Control, Huainan, China \\ Email: 417785981@qq.com
}

How to cite this paper: $\mathrm{Bi}, \mathrm{B}$., Meng, J.B. and Cheng, B.L. (2021) A Study on the Dynamic Adjustment of Pressure Relief Gas Drainage Drilling in Mined-Out Areas. World Journal of Engineering and Technology, 9, 337-345.

https://doi.org/10.4236/wjet.2021.92023

Received: March 23, 2021

Accepted: May 14, 2021

Published: May 17, 2021

Copyright $\odot 2021$ by author(s) and Scientific Research Publishing Inc. This work is licensed under the Creative Commons Attribution International License (CC BY 4.0). http://creativecommons.org/licenses/by/4.0/

\section{Open Access}

\begin{abstract}
With the development of coal mine equipment mechanization, the wide application of "hole instead of roadway" technology greatly reduces the cost of gas control engineering, but puts forward higher requirements for the effect of gas drainage. At present, the drainage effect of coal mine inspection boreholes is mainly evaluated by the drilling field, but the flow rate and gas concentration of each borehole in the drilling field are not the same, which causes the gas drainage effect not to be correctly mastered. In the present study, the pressure relief drilling in the goaf of the working face of a typical multi-coal seam group high gas outburst mining area was taken as the research object. Through the newly developed portable drilling inspection device, the pure amount of drilling drainage was investigated, and the drilling design was dynamically adjusted. The enhancement of the goaf pressure relief gas control effect ensures the gas safety of the mining face. At the same time, this improves the gas extraction rate and reduces the emission of greenhouse gases. If the data from the borehole investigation can be transmitted in real time and analyzed in big data, the optimal extraction negative pressure can be predicted through a regression algorithm. Under the control of the negative pressure of each borehole by the actuator, the extraction system can have the function of intelligent judgment.
\end{abstract}

\section{Keywords}

Pressure-Relief Gas Extraction, Study on the Extraction Effect, Borehole Design, Determination of Pore Parameters

\section{Foreword}

With the development of coal mine equipment mechanization and the improve- 
ment of drilling construction quality, the gas drainage technology for the fully-mechanized mining face "replacing roadway with hole" has been widely used. Although "replacing the roadway with a hole" can greatly reduce the cost of the project, this puts forward higher requirements for the effect of gas drainage. Hence, determining how to examine the quality of drilling construction and optimize the drilling design is particularly important. At present, the extraction effect of gas control boreholes in coal mines is mainly determined by examining the drilling field or evaluation unit, but the flow rate and gas concentration of each borehole in the drilling field are different, which makes it impossible to correctly grasp the gas extraction effect.

In view of the poor application effect of existing drilling inspection devices, and the fact that this cannot timely and accurately reflect the actual drainage situation of the borehole, the present study takes the pressure relief borehole in the goaf of the working face in a typical multi-coal seam group high gas outburst mining area as the research object. Through the newly developed portable drilling inspection device, the drainage parameters of each borehole in the drilling field were separately investigated, and the drilling design was dynamically adjusted, in order to improve the effect of the pressure relief gas control in the goaf and ensure the gas safety of the mining face.

\section{General Situation of the Working Face}

The Panyi Coal Mine is located at the southeast side of the North China Plate. The strike length of 1252 (3) fully mechanized mining face is 1054 meters, the inclination length is 193.50 meters, and the resources are 136 million tons. The coal seam is the No. 13 coal seam of the Upper Shihezi Formation of the Permian, with a coal thickness of $4.00-7.40 \mathrm{~m}$ and an average coal thickness of 4.70 $\mathrm{m}$. The occurrence of the coal seam was $130^{\circ}-170^{\circ}$ and $1^{\circ}-9^{\circ}$, and the structure of the coal seam was complex. The original gas content was $14.20 \mathrm{~m}^{3} / \mathrm{t}$, which is the outburst area. The residual gas content was $3.65 \mathrm{~m}^{3} / \mathrm{t}$, and the residual gas pressure was $0.5 \mathrm{MPa}$, which has no outburst risk.

\section{Configuration and Principle of the Inspection Device}

Based on the principle of velocity and pressure measurement by a pitot tube, the inspection device calculated the flow rate in the drainage pipe, and calculated the pure amount of borehole drainage combined with the measured gas concentration.

Based on the principle of the pitot tube to measure the velocity and pressure, the flow velocity in the drainage hose was inversely calculated, and the measured gas concentration was used to calculate the borehole drainage volume. The equipment had a minimal effect on borehole drainage, and the measurement results were more accurate. At the same time, the multi-point measurement could accurately calculate the problem of uneven distribution of velocity and concentration in the section, which greatly reduced the drainage of the borehole 
itself.

The structure of the inspection device is presented in Figure 1. This included the following: 1) pressure difference measurement tool, 2) pitot tubes for measurement, 3) rubber tubes for the connection, 4) rubber cover for sealing, 5) scale, and 6) mixed gas flow direction. The pitot tube was L-shaped, the edge H1 of the measuring tube was greater than the diameter of the measuring hole, and a scale was required. After the measurement, the sealing rubber cover was installed in the pitot tube.

First, the differential pressure measuring device was connected with hose 2, and the differential pressure measuring device was used to measure the speed pressure $H$ in the drainage pipeline. Second, the differential pressure measuring instrument was removed, and the gas measuring instrument was connected with the rubber tube to measure the gas concentration $C$ in the drainage pipeline. Finally, the velocity $H$ and gas concentration $C$ were measured according to steps 1 and 2. The flow calculation Formula (1) was used to calculate the measured point extraction pure quantity $Q$.

$$
Q_{1-n}=V_{1-n} \times 1 \times C_{1-n}
$$

where: $V$ is the velocity of the measuring point, and the velocity $V$ can be calculated according to Formula (2) of the velocity pressure calculation formula.

$$
V_{1-n}=\sqrt{\frac{2 H_{1-n}}{p}}
$$

where: $p$ measures the average air density in the extraction pipeline, $p=0.83$ $\mathrm{kg} / \mathrm{m}^{3}$ (Figure 2).

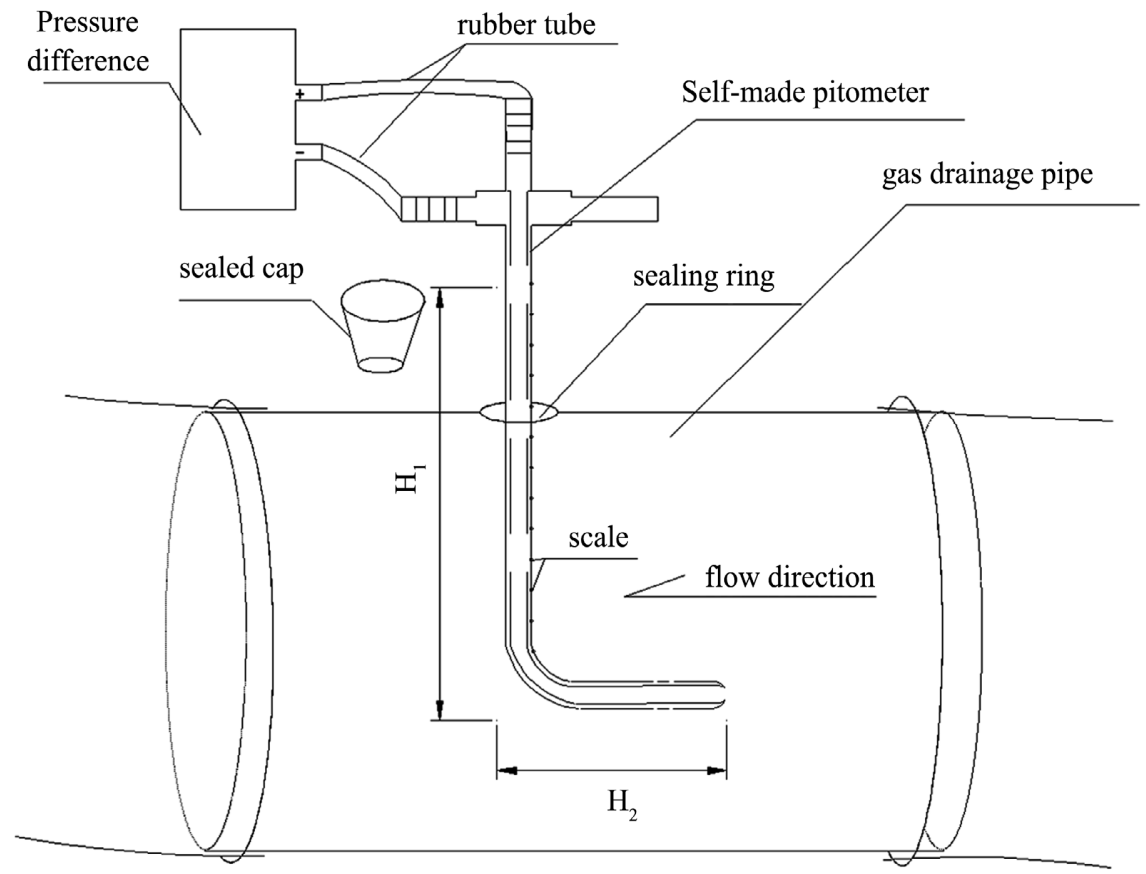

Figure 1. Structure of the inspection device. 


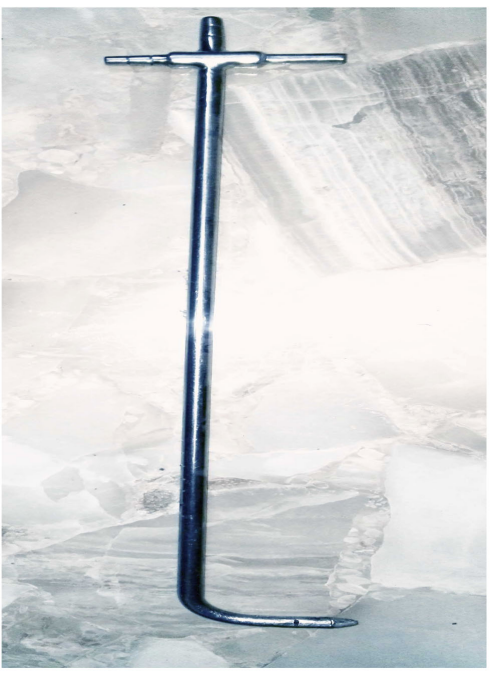

Self-made pitometer

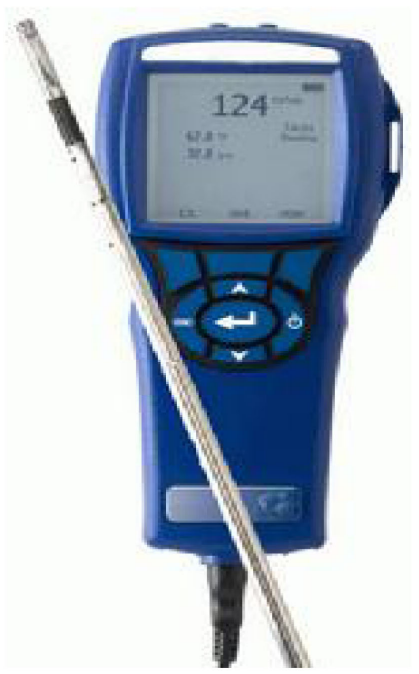

Differential pressure meter

Figure 2. Physical image of the inspection device.

When the flow velocity in the extraction pipeline was fast and the gas concentration distribution was uniform, the two-point measurement method was used. Initially, the pitot tube was inserted (3) to the end, and unit 2 and unit 6 were pulled up, respectively (refer to Figure 3 for the measuring points). The pressure $H_{2}$ and $H_{6}$, and the concentration $C_{2}$ and $C_{6}$ were measured. Then, the empirical Formula 3 was used to calculate the drilling drainage pure quantity $Q$.

$$
Q=\frac{Q_{2}+Q_{6}}{2}
$$

When the flow velocity in the extraction pipeline greatly changed, and the gas concentration distribution was uneven, the four-point measurement method was used. Initially, the custom pitot tube was inserted to the bottom, and the corresponding unit 1, 3, 5 and 7 were respectively pulled up (refer to Figure 4 for the measuring points) to measure the $H_{1}, H_{3}, H_{5}$ and $H_{7}$, and $C_{1}, C_{3}, C_{5}$ and $C_{7}$. Then, $Q_{1}, Q_{3}, Q_{5}$ and $Q_{7}$ were respectively calculated.

The empirical Formula (4) was used to calculate the borehole extraction pure quantity $Q$

$$
Q=\frac{Q_{1} \times 3+Q_{3}+Q_{5}+Q_{7} \times 3}{8}
$$

\section{Field Application}

\subsection{The Drilling Design for the Roof Strike}

According to the movement characteristics of the surrounding rock in the goaf, with the advance of the mining face, three vertical zones were formed in the vertical direction of the goaf. These were classified, as follows, from the bottom to the top: caving zone, fracture zone, and bending subsidence zone. The three transverse zones were formed in the horizontal direction, which were classified, as follows: recompaction zone, separation zone, and coal wall support influence 


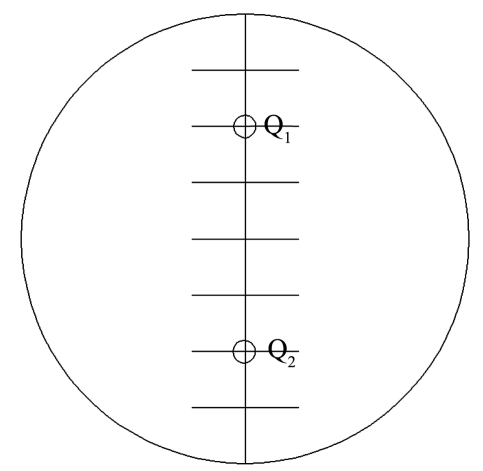

Figure 3. The 2-point test chart.

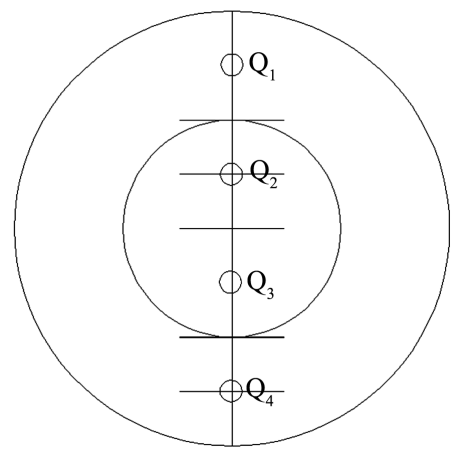

Figure 4. The 2-point test chart.

zone along the advancing direction of the working face [1]. With the advancement of the working face, the roof strata that entered the goaf irregularly ruptured, forming a series of separation and coalescence fractures. Then, a large number of pressure relief gas in the space continuously circulated and accumulated [2]. Of The roof high drilling design goaf roof gas enrichment area can make the drilling longer on the goaf pressure relief high concentration gas drainage [3] [4]. The preliminary design for the return airway was every 30 meters in the coal wall construction drilling field, from the drilling field to the direction of the goaf drilling. According to the traditional formula for the roof fracture zone, the height of the roof fracture zone was calculated as $25-70 \mathrm{~m}$, according to the mining height of $4.70 \mathrm{~m}$. In order to prevent gas accumulation in the upper corner of the working face, the boreholes were arranged within the range of $50 \mathrm{~m}$ from the coal wall of the return airway to the goaf. The final borehole spacing was $8 \mathrm{~m}$, and the horizontal direction was controlled at $110 \mathrm{~m}$. The borehole design is presented in Figure 5, and the initial design parameters for the borehole are presented in Table 1 .

\subsection{Accuracy Verification}

Each borehole was not affected by roof collapse after the drilling construction, and there was no extraction amount and gas concentration. When the working face advanced, the roof of the mined-out area collapsed. Furthermore, the drilling hole was in the fracture area, and drainage flow and gas concentration were 

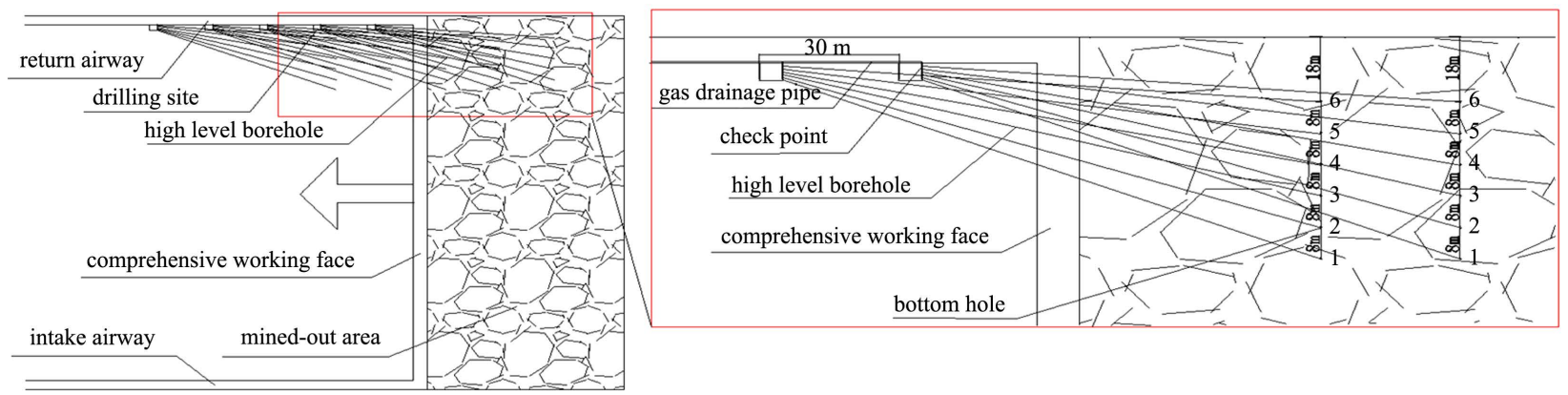

Figure 5. The design drawing of the drilling hole.

Table 1. The initial drilling design parameter.

\begin{tabular}{ccccc}
\hline Drilling number & \multicolumn{2}{c}{ Angle with the middle line } & Dip angle & Drilling depth \\
\hline 1 & Left deviation & $21^{\circ}$ & $17^{\circ}$ & $128.50 \mathrm{~m}$ \\
2 & Left deviation & $18^{\circ}$ & $16^{\circ}$ & $126.50 \mathrm{~m}$ \\
3 & Left deviation & $15^{\circ}$ & $17^{\circ}$ & $124.50 \mathrm{~m}$ \\
4 & Left deviation & $11^{\circ}$ & $16^{\circ}$ & $122.50 \mathrm{~m}$ \\
5 & Left deviation & $8^{\circ}$ & $16^{\circ}$ & $121.50 \mathrm{~m}$ \\
6 & Left deviation & $4^{\circ}$ & $16^{\circ}$ & $120.50 \mathrm{~m}$ \\
\hline
\end{tabular}

present. These remained stable for a certain period of time. The drilling drainage parameters in this period were investigated to evaluate the effect of the drilling construction. When working near the drilling field, the borehole in the drilling field would be directly connected to the goaf due to the collapse of the goaf. At this time, the extraction amount was significant, but there is minimal gas. The effect of the borehole drainage was observed in our examination room. In order to count the amount of gas extractions, the online measurement of gas extraction for each drilling field was carried out, and the gas extraction concentration, flow rate and gas extraction purity of the drilling field were monitored in real time. The \#1 drilling field and \#2 drilling field of the construction working face were tested, and the results are presented in Table 2 .

It can be observed that the measured total mixed flow for the six boreholes using the inspection device in the \#1 drilling field was $13.40 \mathrm{~m}^{3} / \mathrm{min}$. Combined with the gas concentration, the total gas extraction purity was $8.80 \mathrm{~m}^{3} / \mathrm{min}$, and the average gas concentration was $66 \%$. Compared with the automatic metering device for the extraction of the main pipeline of the \#1 drilling field, the gas concentration was $68 \%$, the mixed extraction rate was $13 \mathrm{~m}^{3} / \mathrm{min}$, and the pure gas extraction rate was $8.84 \mathrm{~m}^{3} / \mathrm{min}$. The error between the test results of the device and the automatic metering device for the extraction of the main pipeline was less than $3 \%$. The total mixed flow for the six boreholes measured using the inspection device in the $\# 2$ drilling field was $15.50 \mathrm{~m}^{3} / \mathrm{min}$. Combined with the gas concentration, the total gas extraction purity was $9.60 \mathrm{~m}^{3} / \mathrm{min}$, and the average gas concentration was $62 \%$. Compared with the automatic metering device 
for the extraction of the main pipeline of the \#2 drilling field, the gas concentration was $63 \%$, the mixed extraction rate was $15.60 \mathrm{~m}^{3} / \mathrm{min}$, and the pure gas extraction rate was $9.80 \mathrm{~m}^{3} / \mathrm{min}$. The error between the test results of the device and the automatic metering device for the extraction of the main pipeline was less than $2 \%$. This shows that the accuracy of the single-hole inspection device can meet the optimization requirements of the borehole drainage design.

\subsection{Drilling Design Optimization}

The \#1 - 8 boreholes of the 1252 (3) working face were tested using the investigation device. The test results for the mixed flow and gas concentration of the gas extraction are presented in Figures 6-8. It can be observed that the inclination of the borehole in the \#4 drilling field increased, while the inclination of the borehole in the \#5 drilling field decreased. This led to the small fracture in the extraction position of the \#4 drilling hole and the high gas concentration. The fracture space in the extraction position of the \#5 drilling field was large, and the gas concentration was low, but the total gas extraction was not significantly

Table 2. Test result statistics.

\begin{tabular}{|c|c|c|c|c|c|c|}
\hline \multirow{2}{*}{$\begin{array}{l}\text { Drilling } \\
\text { number }\end{array}$} & \multicolumn{3}{|c|}{ \#1 drilling site } & \multicolumn{3}{|c|}{$\# 2$ drilling site } \\
\hline & $\begin{array}{c}\text { Gas } \\
\text { concentration }\end{array}$ & $\begin{array}{l}\text { Mixing } \\
\text { flow }\end{array}$ & $\begin{array}{l}\text { The } \\
\text { total gas }\end{array}$ & $\begin{array}{c}\text { Gas } \\
\text { concentration }\end{array}$ & $\begin{array}{l}\text { Mixing } \\
\text { flow }\end{array}$ & $\begin{array}{l}\text { The } \\
\text { total gas }\end{array}$ \\
\hline 1 & $70 \%$ & $0.89 \mathrm{~m}^{3} / \mathrm{min}$ & $0.63 \mathrm{~m}^{3} / \mathrm{min}$ & $70 \%$ & $2.19 \mathrm{~m}^{3} / \mathrm{min}$ & $1.52 \mathrm{~m}^{3} / \mathrm{min}$ \\
\hline 2 & $96 \%$ & $3.79 \mathrm{~m}^{3} / \mathrm{min}$ & $3.65 \mathrm{~m}^{3} / \mathrm{min}$ & $43 \%$ & $2.73 \mathrm{~m}^{3} / \mathrm{min}$ & $1.17 \mathrm{~m}^{3} / \mathrm{min}$ \\
\hline 3 & $80 \%$ & $2.42 \mathrm{~m}^{3} / \mathrm{min}$ & $1.94 \mathrm{~m}^{3} / \mathrm{min}$ & $95 \%$ & $2.35 \mathrm{~m}^{3} / \mathrm{min}$ & $2.25 \mathrm{~m}^{3} / \mathrm{min}$ \\
\hline 4 & $43 \%$ & $1.76 \mathrm{~m}^{3} / \mathrm{min}$ & $0.75 \mathrm{~m}^{3} / \mathrm{min}$ & $61 \%$ & $2.05 \mathrm{~m}^{3} / \mathrm{min}$ & $1.24 \mathrm{~m}^{3} / \mathrm{min}$ \\
\hline 5 & $40 \%$ & $1.46 \mathrm{~m}^{3} / \mathrm{min}$ & $0.58 \mathrm{~m}^{3} / \mathrm{min}$ & $22 \%$ & $1.88 \mathrm{~m}^{3} / \mathrm{min}$ & $0.41 \mathrm{~m}^{3} / \mathrm{min}$ \\
\hline 6 & $42 \%$ & $3.08 \mathrm{~m}^{3} / \mathrm{min}$ & $1.30 \mathrm{~m}^{3} / \mathrm{min}$ & $70 \%$ & $4.30 \mathrm{~m}^{3} / \mathrm{min}$ & $3.01 \mathrm{~m}^{3} / \mathrm{min}$ \\
\hline Summary & $66 \%$ & $13.40 \mathrm{~m}^{3} / \mathrm{min}$ & $8.80 \mathrm{~m}^{3} / \mathrm{min}$ & $62 \%$ & $15.50 \mathrm{~m}^{3} / \mathrm{min}$ & $9.60 \mathrm{~m}^{3} / \mathrm{min}$ \\
\hline $\begin{array}{l}\text { Automatic } \\
\text { metering }\end{array}$ & $68 \%$ & $13.00 \mathrm{~m}^{3} / \mathrm{min}$ & $8.84 \mathrm{~m}^{3} / \mathrm{min}$ & $63 \%$ & $15.60 \mathrm{~m}^{3} / \mathrm{min}$ & $9.80 \mathrm{~m}^{3} / \mathrm{min}$ \\
\hline
\end{tabular}

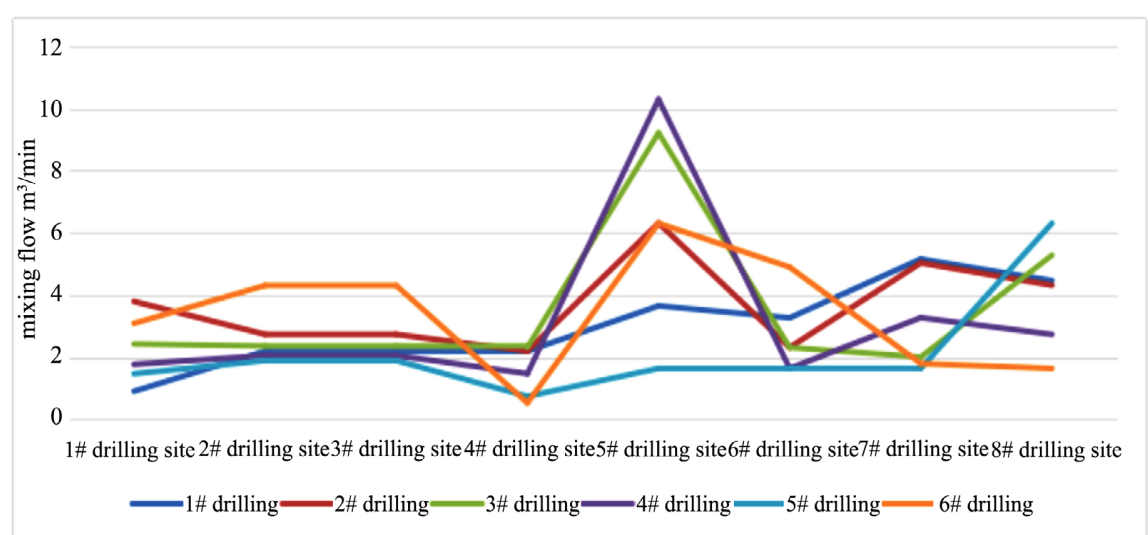

Figure 6. Variation diagram for the mixing flow amount of each drilling. 


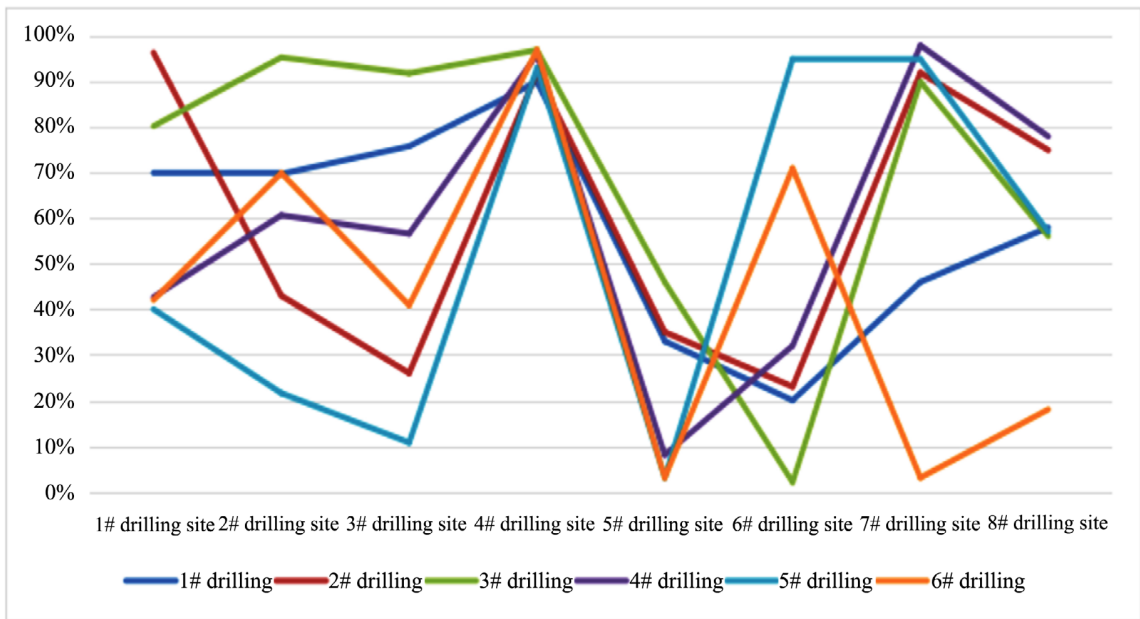

Figure 7. Variation diagram for the gas concentration amount of each drilling.

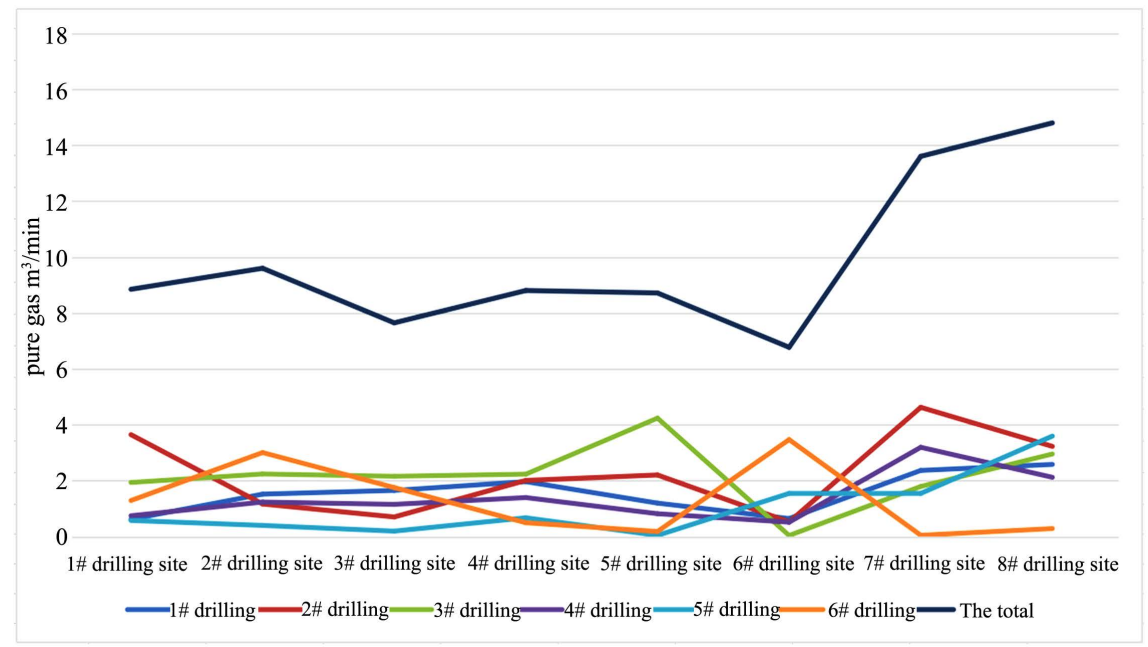

Figure 8. Variation diagram for the total gas amount of each drilling.

different. If merely the total amount of drainage in the drilling field was investigated, the effect of the drilling drainage cannot be analyzed. Hence, there is no way to optimize the design for drilling. According to the extraction effect of each borehole in the first six drilling fields, the total extraction purity was approximately $9 \mathrm{~m}^{3} / \mathrm{min}$. Finally, the final hole height was $30 \mathrm{~m}$ above the roof. After the $\# 7$ and $\# 8$ adopted the borehole inclination of $19^{\circ}$, the gas extraction purity became $14 \mathrm{~m}^{3} / \mathrm{min}$.

\section{Conclusions}

1) Through the extraction analysis of each borehole in the six drilling fields in front of the 1252 (3) using the investigation device, it can be concluded that the stable extraction purity of the drilling field was approximately $9 \mathrm{~m}^{3} / \mathrm{min}$, and that the position of the final hole height at $30 \mathrm{~m}$ above the roof was the best position for extraction. After adjusting the borehole inclination angles in the \#7 and $\# 8$ drilling fields to $19^{\circ}$, the gas extraction purity became $14 \mathrm{~m}^{3} / \mathrm{min}$. 
2) With the wide application of the big data artificial intelligence algorithm, the data inspected by each borehole was transmitted in real time and analyzed by big data, and the optimal negative pressure of the extraction was predicted by regression algorithm. Under the control of the negative pressure of each borehole by the actuator, the extraction system can have the function of intelligent judgment.

\section{Conflicts of Interest}

The authors declare no conflicts of interest regarding the publication of this paper.

\section{References}

[1] Liao, W.T. and Deng, X.Y. (2019) Numerical Simulation of Pressure Relief Gas Flow under Mining Conditions. International Journal of Heat and Technology, 35, 1061 1064. https://doi.org/10.18280/ijht.350443

[2] Liang, R., Chang X.T, Jia, P.T., et al. (2020) Mine Gas Concentration Forecasting Model Based on an Optimized BiGRU Network. ACS Omega, 5, 28579-28586. https://doi.org/10.1021/acsomega.0c03417

[3] Li, S.G. and Lin, H.F. (2004) Migration and Accumulation Characteristic of Methane in Mining Fissure Elliptic Paraboloid Zone. In: Wang, Y.J., Huang, P., Li, S.C.S, Eds., Proceedings of 2004 International Symposium on Safety Science and Technology, Vol. 4, Science Press, Beijing, 576-581.

[4] Beyer, H.A. (1999) Design and Performance of Metrology Cameras with 6 and 28 Million Pixel CCD-Sensors. Proceedings of SPIE, Vol. 3461, San Jose, 194-198. https://doi.org/10.1117/12.333783 